\title{
Salvianolic Acid B Prevents Iodinated Contrast Media-Induced Acute Renal Injury in Rats via the PI3K/Akt/Nrf2 Pathway
}

\author{
Liu Tongqiang, ${ }^{1,2}$ Liu Shaopeng, ${ }^{1,3}$ Yu Xiaofang, ${ }^{1,3}$ Song Nana, ${ }^{1,3}$ Xu Xialian,,3 \\ Hu Jiachang, ${ }^{1,3}$ Zhang Ting, ${ }^{1,3}$ and Ding Xiaoqiang ${ }^{1,3}$ \\ ${ }^{1}$ Division of Nephrology, Zhongshan Hospital, Fudan University, Shanghai 200032, China \\ ${ }^{2}$ Division of Nephrology, The Affiliated Changzhou No. 2 Hospital of Nanjing Medical College, Changzhou, Jiangsu 213003, China \\ ${ }^{3}$ Shanghai Institute of Kidney and Dialysis, Shanghai 200032, China \\ Correspondence should be addressed to Ding Xiaoqiang; ding.xiaoqiang@zs-hospital.sh.cn
}

Received 14 December 2015; Revised 22 February 2016; Accepted 30 March 2016

Academic Editor: Noriko Noguchi

Copyright (C) 2016 Liu Tongqiang et al. This is an open access article distributed under the Creative Commons Attribution License, which permits unrestricted use, distribution, and reproduction in any medium, provided the original work is properly cited.

Contrast-induced acute renal injury (CI-AKI) has become a common cause of hospital-acquired renal failure. However, the development of prophylaxis strategies and approved therapies for CI-AKI is limited. Salvianolic acid B (SB) can treat cardiovascularrelated diseases. The aim of the present study was to assess the effect of SB on prevention of CI-AKI and explore its underlying mechanisms. We examined its effectiveness of preventing renal injury in a novel CI-AKI rat model. Compared with saline, intravenous SB pretreatment significantly attenuated elevations in serum creatinine and the histological changes of renal tubular injuries, reduced the number of apoptosis-positive tubular cells, activated Nrf2, and lowered the levels of renal oxidative stress induced by iodinated contrast media. The above renoprotection of SB was abolished by the PI3K inhibitor (wortmannin). In HK-2 cells, SB activated Nrf2 and decreased the levels of oxidative stress induced by hydrogen peroxide and subsequently improved cell viability. The above cytoprotection of SB was blocked by the PI3K inhibitor (wortmannin) or siNrf2. Thus, our results demonstrate that, due to its antioxidant properties, SB has the potential to effectively prevent CI-AKI via the PI3K/Akt/Nrf2 pathway.

\section{Introduction}

Contrast-induced acute renal injury (CI-AKI) is an important syndrome of acute renal failure occurring after the intravascular administration of radiographic contrast media (CM) in diagnostic and interventional procedures, which is defined as an increase of $25 \%$ or more or an absolute increase of $0.5 \mathrm{mg} / \mathrm{dL}$ or more in serum creatinine (Scr) from baseline value within 3 days after exposure to $\mathrm{CM}$ in the absence of any alternative causes [1]. CI-AKI is the third most common cause of acute renal failure in hospitalized patients [2] and is associated with replacement therapy, prolonged hospitalization, increased medical cost, and increased mortality $[3,4]$. The present evidence indicates that the mechanisms of CI-AKI are thought to be a combination of the direct tubular toxicity of $\mathrm{CM}$, renal medullary ischaemia, and generation of reactive oxygen species (ROS), in which ROS seem to represent the primary event in the pathogenesis of CI-AKI $[4,5]$.
Moreover, antioxidant-mediated protection of renal function with specific drugs provides indirect evidence that oxidative stress is considered to be involved in the pathogenesis of CIAKI $[6,7]$.

Salvianolic acid B (SB) is one of the main components of Danshen (root of Salvia miltiorrhiza) [8], a widely used traditional Chinese medicine. Previous studies have shown that $\mathrm{SB}$ has antioxidative activity in vivo and in vitro $[9,10]$. However, its mechanism for antioxidative damage is still not clear. It was reported that SB activated the PI3K/Akt signaling pathway [11] and induced nuclear factor erythroid 2-related factor 2 (Nrf2), heme oxygenase 1 (HO-1), and glutamate-l-cysteine ligase catalytic subunit (GCLC) expression, thereby protecting against APAP-induced liver injury and protecting dopaminergic neurons by an Nrf2-mediated action $[9,12]$. Activation of the PI3K/Akt/Nrf2 pathway could protect against cell and organ injury through upregulation of antioxidant enzyme and phase II detoxification enzyme 
expression (e.g., HO-1; GCLC; and quinone oxidoreductase (NQO1)) [13].

Therefore, we hypothesized that SB could prevent AKI induced by $\mathrm{CM}$ because of its antioxidative effects. In the present study, the effects of SB on CI-AKI and its underlying mechanisms were investigated in an experimental model of CI-AKI in rats and human proximal tubule (HK-2) cells. Our results suggest that $\mathrm{SB}$ prevents $\mathrm{CI}-\mathrm{AKI}$ by reducing oxidative stress through the PI3K/Akt/Nrf2 pathway.

\section{Materials and Methods}

2.1. Chemicals and Reagents. Iohexol (low-osmolarity nonionic CM, $350 \mathrm{mg}$ iodine/mL, GE Healthcare, Shanghai, China), SB (purity $>98.0 \%$, kindly donated from Shanghai Green Valley Pharm. Co., Ltd.), wortmannin (Abcam Inc., Cambridge, MA, USA), sulforaphane (SFN, LKT Laboratories Inc., St. Paul, USA), Nrf2 siRNA (Santa Cruz, CA, USA), control siRNA (Santa Cruz, CA, USA), Opti-MEM I (Invitrogen, CA, USA), and Lipofectamine 2000 solution (Invitrogen, CA, USA) were used in this study.

2.2. Animals and Grouping. Male Sprague-Dawley rats (180$200 \mathrm{~g}$ ) obtained from the Animal Center of Fudan University, Shanghai, China. The rats were acclimatized for $7 \mathrm{~d}$ before the start of study and handled in accordance with the institutional and national guidelines for animal research. A novel, reliable, and suitable CI-AKI model based on the 5/6 nephrectomy (NE) rat was established as in our previous reports [14, 15]. In brief, the CI-AKI model used 5/6 NE rats 6 weeks after an ablative surgery and was established by dehydration for $48 \mathrm{~h}$, followed by administration of $10 \mathrm{~mL} / \mathrm{kg}$ body weight $(3.5 \mathrm{gI} / \mathrm{kg})$ iohexol via the tail vein. All animals had ad libitum access to water and food after the injection.

\subsubsection{Part 1: The Role of SB in Renoprotection against Iohexol.} Thirty-two rats with similar levels of renal function 6 weeks after 5/6 NE procedure were selected and randomly divided into the following four equal groups ( $n=8$ in each): (1) saline group: administered vehicle and $10 \mathrm{~mL} / \mathrm{kg} 0.9 \%$ saline; (2) SB + saline group: administered $50 \mathrm{mg} / \mathrm{kg} \mathrm{SB}$ and $10 \mathrm{~mL} / \mathrm{kg} 0.9 \%$ saline; (3) CM group: administered vehicle and $10 \mathrm{~mL} / \mathrm{kg}$ iohexol; and (4) SB + CM group: administered $50 \mathrm{mg} / \mathrm{kg} \mathrm{SB}$ and $10 \mathrm{~mL} / \mathrm{kg}$ iohexol. Intravenous injection of SB and vehicle was performed $5 \mathrm{~min}$ prior to the intravenous injection of saline or iohexol. Scr, blood urea nitrogen (BUN), and tissue morphology were assessed at $24 \mathrm{~h}$ after the last injection.

2.2.2. Part 2: The Role of the PI3K/Akt/Nrf2 Pathway in Renoprotection Induced by $S B$. Eighty rats with similar levels of renal function 6 weeks after the ablative surgery were selected and randomly divided into the following six equal groups (the CM and SB (or vehicle) were administered as described above): (1) CM group; (2) SB + CM group; (3) Wort + CM group: treated with wortmannin $(15 \mu \mathrm{g} / \mathrm{kg})$ [15], vehicle, and iohexol $(10 \mathrm{~mL} / \mathrm{kg})$; and (4) Wort $+\mathrm{SB}+\mathrm{CM}$ group: treated with wortmannin $(15 \mu \mathrm{g} / \mathrm{kg}), \mathrm{SB}$, and iohexol $(10 \mathrm{~mL} / \mathrm{kg})$; and (5) SFN + CM group: treated with SFN $(10 \mathrm{mg} / \mathrm{kg})$ [16] and iohexol $(10 \mathrm{~mL} / \mathrm{kg})$. Intravenous injection of the pharmacological inhibitors, vehicle, or SFN was performed $5 \mathrm{~min}$ prior to the SB or iohexol. The rats in each group were randomly divided into two equal subgroups $(n=8$ in each). Rats of one subgroup were used for the detection of p-Akt/Akt and Nrf2 by Western blotting at $3 \mathrm{~h}$ after the last injection. This time point was selected because a preliminary experiment showed that the SB-induced p-Akt and nuclearNrf2 levels in kidney tissue peaked at $3 \mathrm{~h}$ and were maintained for $24 \mathrm{~h}$ in CI-AKI rats. The rats in the other subgroup were used for the detection of Scr, and haematoxylin and eosin (HE) staining and terminal deoxynucleotidyl transferasemediated dUTP nick-end labeling (TUNEL) analysis of the kidneys tissue was performed at $24 \mathrm{~h}$ after the last injection.

2.3. Cell Culture and Treatment. HK-2 cells (American Type Culture Center, Manassas, Virginia), a human proximal tubular cell line, were cultured at $37^{\circ} \mathrm{C}$ in $5 \%$ humidified $\mathrm{CO}_{2}$ in Dulbecco's modified Eagle's medium supplemented with $10 \%$ fetal calf serum. Our preliminary study showed that the $\mathrm{H}_{2} \mathrm{O}_{2}$-induced ROS production peaked at $3 \mathrm{~h}$ and subsequently decreased cell viability at $12 \mathrm{~h}$. Therefore, we evaluated cellular ROS levels at $3 \mathrm{~h}$ and cell viability at $24 \mathrm{~h}$ after treatment with $\mathrm{H}_{2} \mathrm{O}_{2}$. Specific targeted siRNA (siNrf2) was used in this part. Our preliminary study showed that the expression of nuclear-Nrf2 was decreased to approximately $20 \%$ of that in the control siRNA-transfected HK-2 cells.

The groups were as follows: (1) control group: the cells were treated with phosphate-buffered saline (PBS); (2) $\mathrm{H}_{2} \mathrm{O}_{2}$ group: cells were treated with $250 \mathrm{mM} \mathrm{H}_{2} \mathrm{O}_{2}$ for $3 \mathrm{~h}$ or $24 \mathrm{~h}$; (3) SB group: cells were treated with $50 \mu \mathrm{M}$ SB for $1 \mathrm{~h}$; (4) $\mathrm{SB}+\mathrm{H}_{2} \mathrm{O}_{2}$ group: cells were treated with $50 \mu \mathrm{M}$ SB for $1 \mathrm{~h}$ and then treated with $250 \mathrm{mM} \mathrm{H}_{2} \mathrm{O}_{2}$ for $3 \mathrm{~h}$ or $24 \mathrm{~h}$; (5) Wort group: cells were treated with an inhibitor (wortmannin, $10 \mu \mathrm{M}$ ) for $1 \mathrm{~h}$; (6) Wort $+\mathrm{SB}+\mathrm{H}_{2} \mathrm{O}_{2}$ group: cells were treated with an inhibitor (wortmannin, $10 \mu \mathrm{M}$ ) and $50 \mu \mathrm{M}$ SB for $1 \mathrm{~h}$ and then treated with $250 \mathrm{mM} \mathrm{H}_{2} \mathrm{O}_{2}$ for $3 \mathrm{~h}$ or $24 \mathrm{~h}$; (7) siCTRL $+\mathrm{SB}+\mathrm{H}_{2} \mathrm{O}_{2}$ group: control siRNA were dissolved separately in Opti-MEM I. After $10 \mathrm{~min}$ of equilibration at room temperature, each RNA solution was combined with the respective volume of the Lipofectamine 2000 solution, mixed gently, and allowed to form siRNA liposomes for $20 \mathrm{~min}$. The primary cultured cells were transfected with the transfection mixture in antibiotic-free cell culture medium for $6 \mathrm{~h}$; then the cells were treated with $50 \mu \mathrm{M}$ SB for $1 \mathrm{~h}$ and finally treated with $250 \mathrm{mM} \mathrm{H} \mathrm{H}_{2} \mathrm{O}_{2}$ for $3 \mathrm{~h}$ or $24 \mathrm{~h}$; and (8) siNrf2 $+\mathrm{SB}+\mathrm{H}_{2} \mathrm{O}_{2}$ group: cells were treated with $\mathrm{Nrf2}$ siRNA, $\mathrm{SB}$, and $\mathrm{H}_{2} \mathrm{O}_{2}$ as above protocol. Vehicle also was performed according to the experimental requirements.

2.4. Measurement of Cellular ROS Levels. CM-H2DCFCA, a ROS sensitive fluorescent dye, was used to measure ROS levels. To evaluate the effect of $\mathrm{SB}$ on $\mathrm{H}_{2} \mathrm{O}_{2}$-induced ROS production, $\mathrm{HK}-2$ cells were cultured in 96 -well plates. $5 \mathrm{mM}$ CM-H2DCFCA was added to each well and incubated for 30 min in Dulbecco's PBS. Fluorescence intensities were measured at an excitation wavelength of $485 \mathrm{~nm}$ and an emission wavelength of $535 \mathrm{~nm}$ using a microplate fluorescence reader. 
2.5. Measurement of HK-2 Cell Viability. HK-2 cell viability was assessed using a CCK-8 assay kit (Beyotime Institute of Biotechnology, Shanghai, China). Cells were cultured in 96-well plates. Approximately $10 \mu \mathrm{L}$ of CCK-8 solution was added to each well and incubated for $4 \mathrm{~h}$ at $37^{\circ} \mathrm{C}$. Fluorescence intensities were measured at an excitation wavelength of $485 \mathrm{~nm}$ and an emission wavelength of $535 \mathrm{~nm}$ using a microplate fluorescence reader. The viability of HK-2 cells was quantified by fluorescence intensities using a spectrophotometer (Model 680 Microplate Reader, Berkeley, California).

2.6. Detection of Rat Serum Biomarkers. Approximately $0.5 \mathrm{~mL}$ of blood was collected from the jugular vein or the abdominal aorta. The blood was centrifuged at $2000 \mathrm{~g}$ for 10 min to obtain the serum. The Scr and BUN concentrations were determined using a Hitachi 7060 chemistry analyzer by a Jaffe method.

2.7. HE Staining. The kidney specimens were fixed in $4 \%$ formalin for $24 \mathrm{~h}$ and embedded in paraffin. Three $\mu \mathrm{m}$ thick tissue sections were cut and stained with $\mathrm{HE}$ for morphologic analysis. A pathologist blinded to the study protocol analyzed the sections using a light microscope (Leica DM 6000 B; Leica Microsystems, Wetzlar, Germany). For semiquantitative analysis of morphological changes, we randomly selected 10 high-magnification $(\times 200)$ fields of the cortex and the outer stripe of the outer medulla. The extent of foamy degeneration and detachment of tubular cells was graded with an arbitrary score of $0-4$ as follows $[14,15]$ : no injury (0); mild: $0-25 \%$ (1); moderate: $25-50 \%$ (2); severe: $50-75 \%$ (3); and very severe: $75-100 \%$ (4).

2.8. TUNEL Assay. For TUNEL staining, $3 \mu \mathrm{m}$ paraffinized sections of the renal corticomedullary boundary zone were performed using a commercial kit (In Situ Cell Death Detection Kit; Roche, Basel, Switzerland) in accordance with the manufacturer's instructions. The sections were fixed in acetone for $10 \mathrm{~min}$, washed in PBS, and immersed in a solution of $3 \% \mathrm{H}_{2} \mathrm{O}_{2}$ for endogenous peroxidase blocking. Incubation with the TUNEL reaction mixture was then performed for $60 \mathrm{~min}$. TUNEL-positive cells were shown with $3,3^{\prime}$ diaminobenzidine; sections were counterstained with hematoxylin. One hundred cells and the percentage of TUNELpositive apoptotic cells were counted in five different fields $(\times 200)$ per tissue slide under a light microscope by a pathologist in a blinded fashion.

2.9. Total and Nuclear Protein Extraction. The renal tissue or cultured cells were divided into two equal portions. One half was prepared in ice-cold lysis buffer $(50 \mathrm{mM}$ TrisHCL pH 6.8, $150 \mathrm{mM} \mathrm{NaCl}, 5 \mathrm{mM}$ EDTA, $0.5 \%$ sodium deoxycholate, $0.5 \% \mathrm{NP}-40$, and a protease inhibitor cocktail) using a homogenizer on ice. After centrifuging at $12,000 \mathrm{~g}$ for $15 \mathrm{~min}$ at $4^{\circ} \mathrm{C}$, the supernatant containing the total protein extract was collected. The other half was prepared in an icecold hypotonic buffer (containing protease and phosphatase inhibitors, DTT, and detergent) using a homogenizer and centrifuged at $14,000 \mathrm{~g}$ for $30 \mathrm{~s}$ at $4^{\circ} \mathrm{C}$. The nuclear pellet was resuspended in $50 \mu \mathrm{L}$ of complete lysis buffer, incubated on ice for $30 \mathrm{~min}$, and centrifuged at $14,000 \mathrm{~g}$ for $10 \mathrm{~min}$ at $4^{\circ} \mathrm{C}$. The supernatant containing the nuclear protein extract was collected, and the protein concentrations were determined using a BCA Protein Assay Reagent Kit (Beyotime Institute of Biotechnology, Shanghai, China).

2.10. Western Blot Assay. Equal amounts of proteins $(40 \mu \mathrm{g}$ total protein or $80 \mu \mathrm{g}$ nuclear protein per lane) were loaded onto a $12.5 \%$ gradient Tris-HCl SDS polyacrylamide gel and then transferred to a PVDF membrane. Nonspecific binding to the membrane was blocked for $1 \mathrm{~h}$ at room temperature with $5 \%$ nonfat milk in $1 \times$ TBS, followed by incubation with primary antibodies against total Akt (rabbit monoclonal 1:1000; Cell Signaling Technology, Danvers, MA), p-Akt (Ser473, rabbit monoclonal 1:2,000; Cell Signaling Technology), Nrf2 (mouse monoclonal 1:1000; Abcam Inc., Cambridge, MA, USA), heme oxygenase 1 (HO-1, mouse monoclonal 1:500; Abcam), $\beta$-actin (mouse monoclonal polyclonal 1:1,000; Abcam), or Histone H3 (mouse monoclonal polyclonal 1:500; Abcam) overnight at $4^{\circ} \mathrm{C}$. After washing with TBST three times, membranes were incubated with horseradish peroxidase-conjugated rabbit or goat secondary antibody (1:10000 dilution; Kang Chen Biotechnology, Guangzhou, China) for $1 \mathrm{~h}$ at room temperature, followed by three washes for $10 \mathrm{~min}$ each. Blots were developed using enhanced chemiluminescent reagents (Thermo Fisher Scientific, Pittsburgh, PA, USA) and target band density was scanned using a LAS-3000 detection system. Image J software was used to analyze band intensities. The results were normalized to the protein levels of $\beta$-actin or Histone H3.

\subsection{Immunohistochemical Staining for Nrf2 and the Oxidized} Derivative (8-Hydroxydeoxyguanosine, 8-OHdG). Immunohistochemical staining was performed on $3 \mu \mathrm{m}$ paraffinized sections. The samples were cleared in xylene and rehydrated in a series of ethanol washes. Endogenous peroxidase activity was inhibited with $3 \% \mathrm{H}_{2} \mathrm{O}_{2}$ for $10 \mathrm{~min}$ and then treated with normal goat serum $(1: 20)$ for $20 \mathrm{~min}$. Next, the samples were incubated with anti-Nrf2 antibody (mouse monoclonal 1:200; Abcam) or anti-8-OHdG antibody (mouse monoclonal 1:100; Abcam) at $4^{\circ} \mathrm{C}$ overnight. The sections were then incubated with a horseradish peroxidaseconjugated secondary antibody (anti-mouse IgG). After rinsing three times with PBS, the sections were stained with $3,3^{\prime}$-diaminobenzidine and then counterstained with hematoxylin. The stained specimens were assessed under a light microscope by a pathologist in a blinded fashion. We randomly selected five high-magnification $(\times 200)$ fields of the renal corticomedullary boundary zone. The specimens were scored according to the percentage of $\mathrm{Nrf2}$ and 8 -OHdG positive cells.

2.12. Lipid Peroxidation/ROS Production. Malondialdehyde (MDA) is a naturally occurring product of lipid peroxidation and an indicator of ROS production. MDA cannot cover all unsaturated aldehydes and ketones produced by oxidative damage and lipid peroxidation. Nonlipid TBARS may 


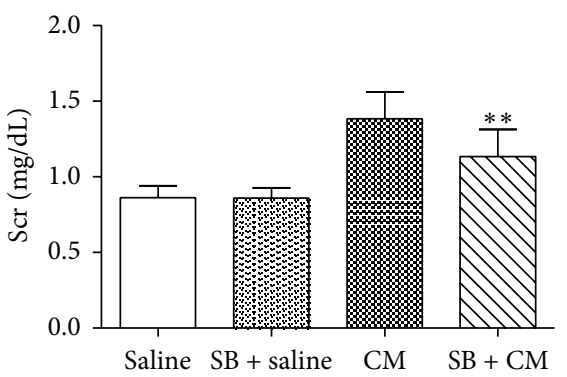

(a)

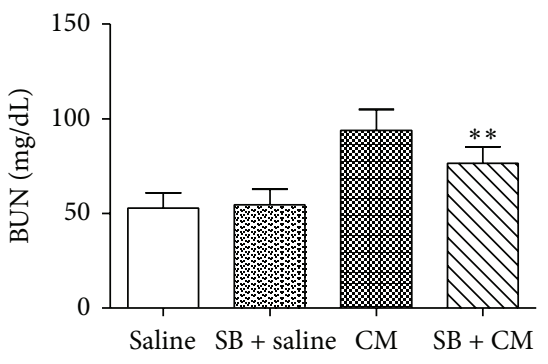

(b)

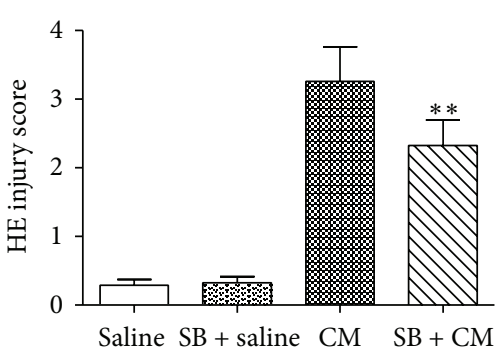

(c)

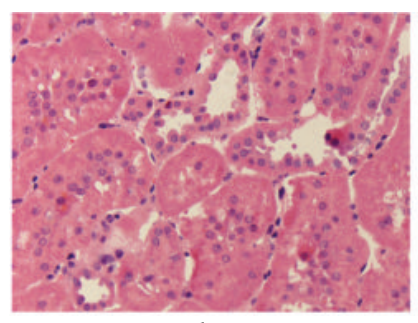

Saline

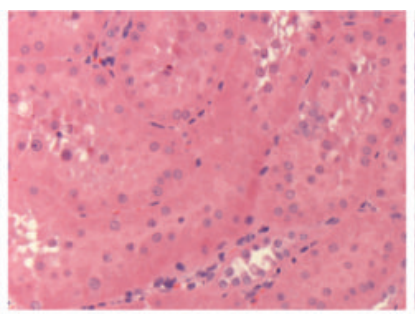

$\mathrm{SB}+$ saline

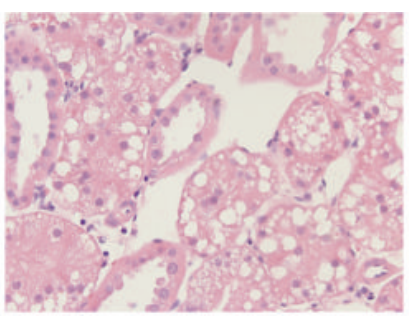

$\mathrm{CM}$

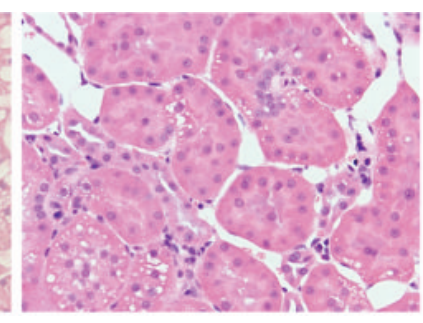

$\mathrm{SB}+\mathrm{CM}$

(d)

FIGURE 1: Protective effects of SB against CI-AKI. SB (50 mg/kg) ameliorated CM-induced increase in (a) the Scr level, (b) the BUN level, and (c) histologic injury scoring at $24 \mathrm{~h}$ after the intravenous injection of $10 \mathrm{~mL} / \mathrm{kg}$ iohexol (350). (d) Representative histological image of kidney from representative photomicrographs of tubular cell injury in rat kidney tissue sections. SB significantly attenuated the renal tubular injury at $24 \mathrm{~h}$ after the injection of iohexol. Original magnification: $\times 200$. HE staining. ${ }^{* *} p<0.01$ versus the CM group; $n=8$. The values shown are the mean \pm SD.

be present in the sample. Therefore, MDA is not specific to lipid peroxidation. However, it is is widely used and is still a good indicator of oxidative stress. The dissected kidneys were immediately rinsed in ice-cold PBS. Tissues were homogenized in $10 \% 150 \mathrm{mM}$ phosphate buffer $(\mathrm{pH}$ 7.4) $(1 / 10 \mathrm{w} / \mathrm{v})$. The homogenate was centrifuged at $6000 \mathrm{~g}$ for $10 \mathrm{~min}$ at $4^{\circ} \mathrm{C}$. The total protein level in the supernatant was measured using a BCA Protein Assay Reagent Kit (Beyotime Institute of Biotechnology, Shanghai, China). The supernatant of the renal cortical homogenate was used to estimate lipid peroxidation according to the manufacturer's protocol (TBARS Assay Kit; Cayman Chemical Company, Ann Arbor, Michigan, USA). The level of lipid peroxides was expressed as nmol of MDA/g of kidney.

2.13. Statistical Analysis. Data are expressed as the means \pm SD. Data were analyzed by one-way ANOVA with Tukey's multiple comparison (parametric tests) or Kruskal-Wallis test with Dunns' multiple comparison (nonparametric tests). Statistical significance of difference was defined as a $p$ value $<0.05$.

\section{Results}

3.1. Renoprotective Effect of SB on Contrast-Induced Nephropathy. The rat in the CM group exhibited elevations in $\mathrm{Scr}$ and BUN $24 \mathrm{~h}$ after iohexol injection (Figures 1(a) and 1(b)). The levels of Scr and BUN in the SB + CM group were markedly decreased compared with the CM group (Scr, 1.13 \pm $0.18 \mathrm{mg} / \mathrm{dL}$ versus $1.39 \pm 0.18 \mathrm{mg} / \mathrm{dL} ; p<0.01 ; \mathrm{BUN}, 76.5 \pm$
$8.7 \mathrm{mg} / \mathrm{dL}$ versus $93.9 \pm 11.1 \mathrm{mg} / \mathrm{dL} ; p<0.01)$. The $\mathrm{CM}$ group showed severe tubular damage (detachment and foamy degeneration of tubular cells). The animals in the SB + CM groups showed significantly lower histologic injury scores in terms of tubular epithelium degeneration than those in the CM group (histologic scoring, $2.32 \pm 0.37$ versus $3.26 \pm 0.50$; $p<0.01$ ) (Figures 1(c) and 1(d)).

3.2. SB-Mediated Renoprotection against Iohexol-Induced Injury through the PI3K/Akt/Nrf2 Pathway in Rats. To explore whether the PI3K/Akt/Nrf2 pathway is involved in the renoprotection provided by $\mathrm{SB}$, a specific inhibitor of PI3K (wortmannin) and an activator of Nrf2 (sulforaphane) [17] were used in this experiment. Scr levels in the Wort $+\mathrm{SB}+$ CM group were also significantly increased in comparison with those in the $\mathrm{SB}+\mathrm{CM}$ group $(\Delta \mathrm{Scr}, 0.46 \pm 0.07 \mathrm{mg} / \mathrm{dL}$ versus $0.27 \pm 0.10 \mathrm{mg} / \mathrm{dL} ; p<0.01$ ) (Figure $2(\mathrm{a})$ ). Scr levels in the SFN + CM group were not significantly different from those in the $\mathrm{SB}+\mathrm{CM}$ group $(\Delta \mathrm{Scr}, 0.24 \pm 0.10 \mathrm{mg} / \mathrm{dL}$ versus $0.27 \pm 0.10 \mathrm{mg} / \mathrm{dL} ; p>0.01$ ) (Figure 2(a)). Rats in the Wort $+\mathrm{SB}+\mathrm{CM}$ group showed severe renal histological alterations $24 \mathrm{~h}$ after the iohexol injections compared with the SB + CM group (histologic scoring, $3.23 \pm 0.38$ versus $2.35 \pm 0.43 ; p<0.05$ ) (Figures $2(\mathrm{~b})$ and $2(\mathrm{~d})$ ). The renal histological alterations in rats in the SFN + CM group were not significantly different from that of the SB + CM group $(2.44 \pm 0.37$ versus $2.35 \pm 0.43 ; p>0.05)$ (Figures 2(b) and $2(\mathrm{~d}))$. TUNEL staining was performed to evaluate the levels of apoptosis in renal cells. The number of TUNELpositive cells in the Wort $+\mathrm{SB}+\mathrm{CM}$ group was markedly 


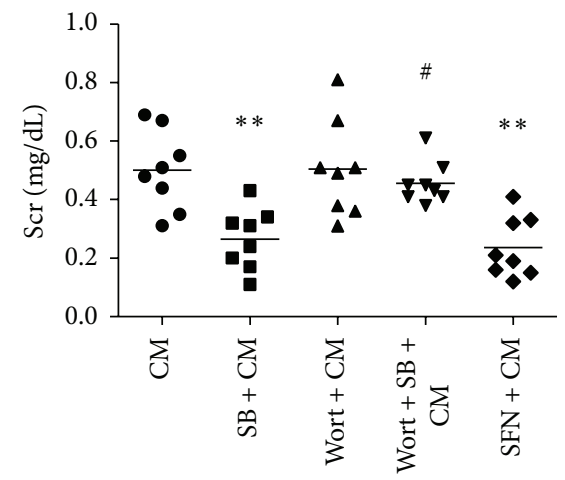

(a)

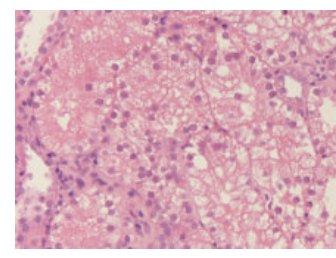

$\mathrm{CM}$

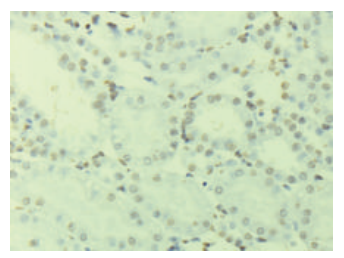

$\mathrm{CM}$

$\mathrm{SB}+\mathrm{CM}$

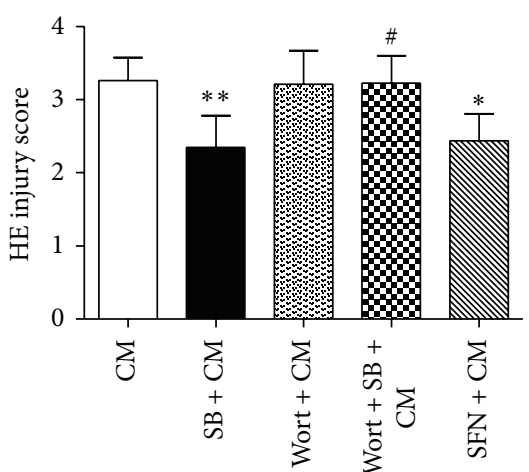

(b)

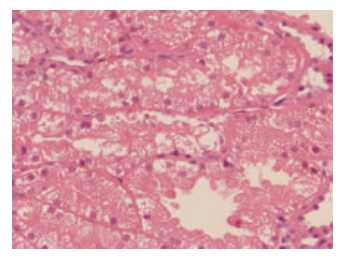

Wort + CM

(d)

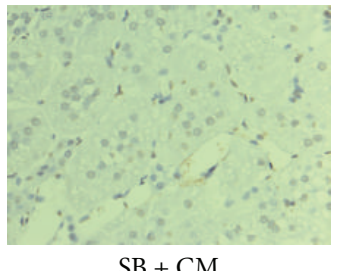

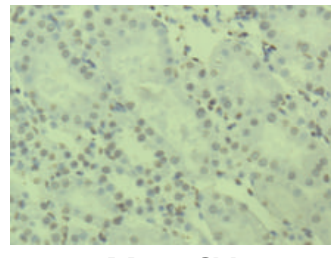

Wort + CM

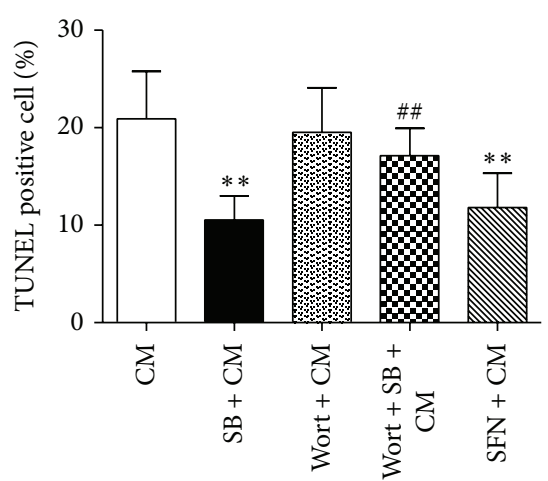

(c)

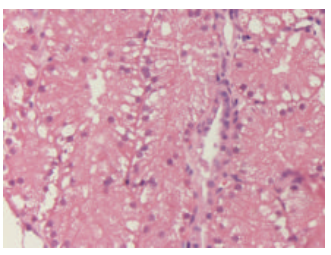

Wort $+\mathrm{SB}+\mathrm{CM}$

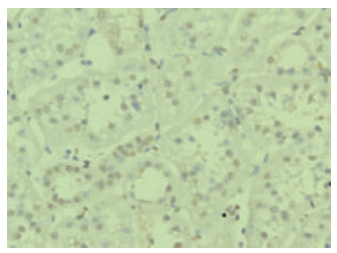

Wort $+\mathrm{SB}+\mathrm{CM}$

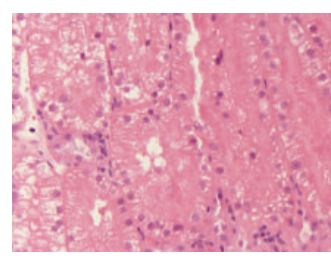

$\mathrm{SFN}+\mathrm{CM}$

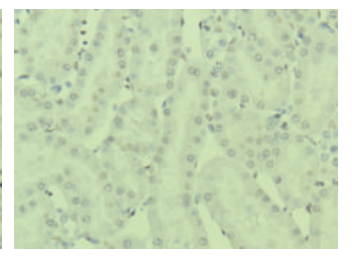

$\mathrm{SFN}+\mathrm{CM}$

(e)

FIGURE 2: SB-induced renoprotection against CI-AKI involves the PI3K/Akt/Nrf2 pathway. (a) A marked reduction in $\Delta$ Scr was induced by $\mathrm{SB}$ in the rats $24 \mathrm{~h}$ after intravenous injection of $10 \mathrm{~mL} / \mathrm{kg}$ iohexol (350). This effect of SB was abolished by treatment with a specific inhibitor of PI3K (wortmannin) and an activator of Nrf2 (SFN) could mimic the effect of SB. (b, d) Representative photomicrographs of tubular cell injury in rat kidney tissue sections and quantitative analysis of histologic scoring (HE staining). SB significantly attenuated renal tubular injury $24 \mathrm{~h}$ after injection of iohexol. This effect of SB was abolished by treatment with wortmannin, and SFN could mimic the effect of SB. $(c, e)$ Representative photomicrographs of immunohistochemical staining for TUNEL in renal sections and quantitative analysis of TUNELpositive cells. The TUNEL-positive staining was localized in nuclei. SB significantly decreased the number of TUNEL-positive cells in rat kidney tissue sections $24 \mathrm{~h}$ after the injection of iohexol. This effect of SB was inhibited by treatment with wortmannin and SFN could mimic the effect of SB. Original magnification $(\mathrm{d}, \mathrm{e}): \times 200{ }^{*}{ }^{*} p<0.05$ and ${ }^{* *} p<0.01$ versus the CM group; ${ }^{*} p<0.05$ and ${ }^{\# \#} p<0.01$ versus the SB $+\mathrm{CM}$ group; $n=8$. The values shown are the mean $\pm \mathrm{SD}$.

increased compared with the the $\mathrm{SB}+\mathrm{CM}$ group (percentage of TUNEL-positive cells, $17.13 \pm 2.82$ versus $10.53 \pm 2.47, p<$ 0.01 ) (Figures 2(c) and 2(e)). The number of TUNEL-positive cells in the renal sections in the SFN + CM group was not significantly different from the $\mathrm{SB}+\mathrm{CM}$ group $(11.83 \pm 3.49$ versus $10.53 \pm 2.47, p>0.05$ ) (Figures $2(\mathrm{c})$ and $2(\mathrm{e})$ ).

3.3. SB Reduced the Levels of Oxidative Stress, through Activation of Nrf2/HO-1, Which Was Abolished by Wortmannin, and Sulforaphane Mimicked This Effect of SB. SB is reported to exert antioxidative and organ-protective effects. To investigate whether SB decreases oxidative stress, the level of an oxidized nucleotide derivative (8-OhdG) in kidney sections and the amount of the lipid peroxidation final reaction substance (MDA) in the supernatants of renal cortical homogenates were determined.
The kidney tissue sections were taken in order to determine the immunohistological staining for 8-OhdG. Immunohistochemical staining showed that the 8-OhdG was expressed in the cell nucleus of kidney cell. The number of 8OhdG-positive cells in the SB + CM group was significantly lower than those in the CM group (percentage of 8-OhdGpositive cells, $15.45 \pm 4.63$ versus $29.03 \pm 6.45, p<0.01$ ) (Figures 3(a) and 3(c)). Furthermore, the levels of MDA in the kidneys of the SB + CM group were significantly lower than those in the CM group $(0.99 \pm 0.16$ versus $1.41 \pm 0.23$, $p<0.01$ ) (Figure $3(\mathrm{~d})$ ).

To further explore the antioxidative effects of Nrf2, sulforaphane was used in this experiment. We found that sulforaphane decreased the levels of oxidative stress (mimicking the effects of SB) (Figures 3(a), 3(c), and 3(d)). In 


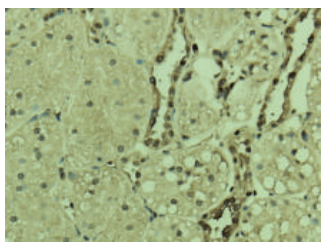

$\mathrm{CM}$

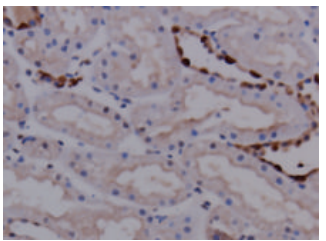

$\mathrm{CM}$

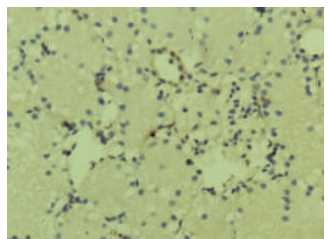

$\mathrm{SB}+\mathrm{CM}$

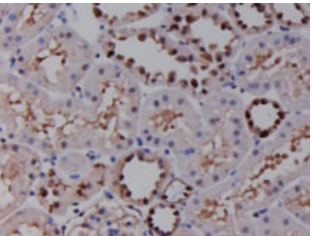

$\mathrm{SB}+\mathrm{CM}$

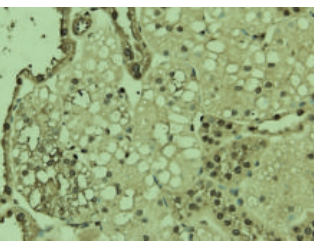

Wort + CM

(a)

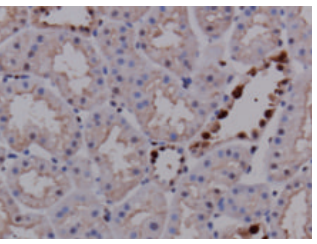

Wort + CM

(b)

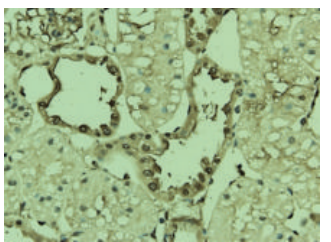

Wort + SB + CM

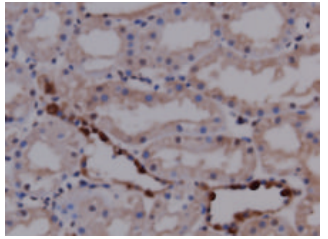

Wort + SB + CM

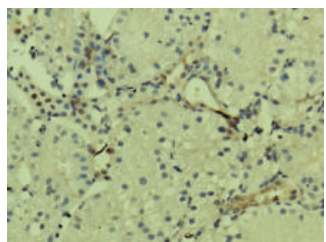

$\mathrm{SFN}+\mathrm{CM}$

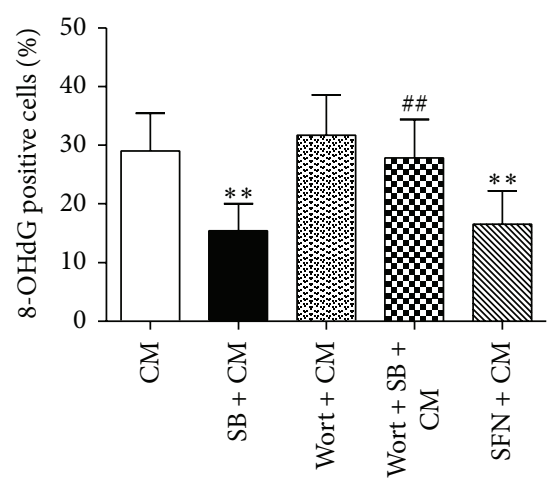

(c)

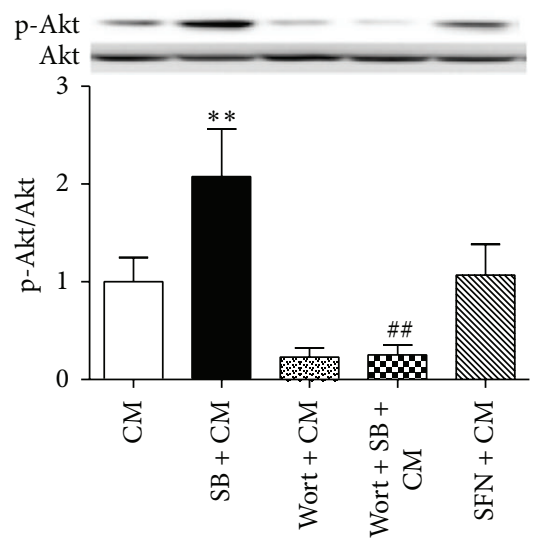

(f)

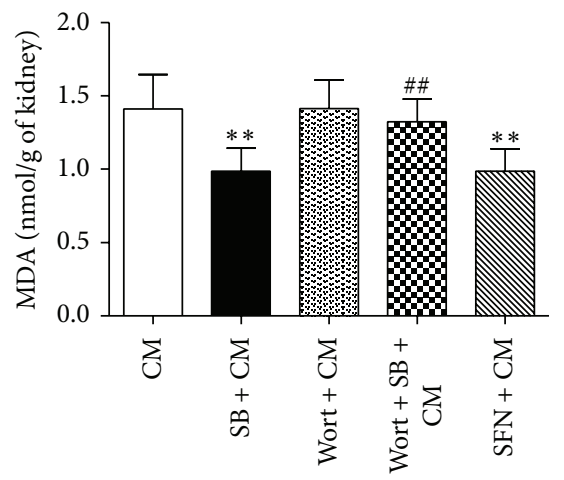

(d)

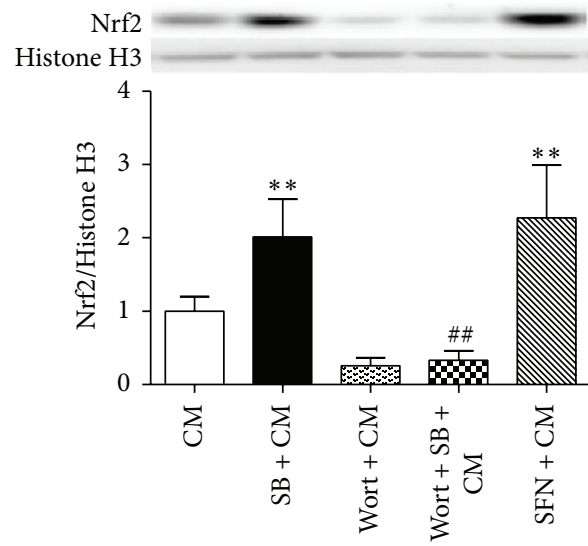

(g)

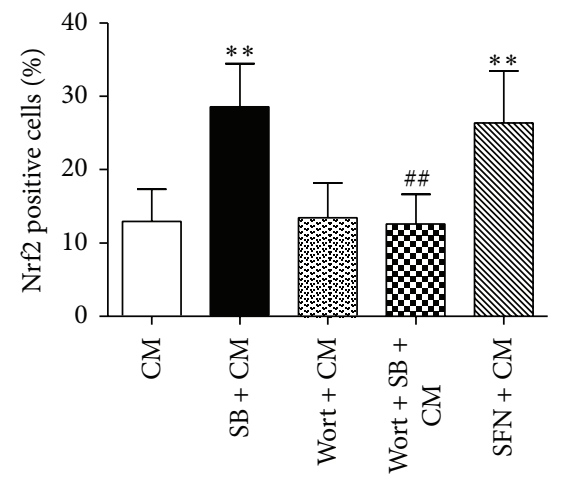

(e)

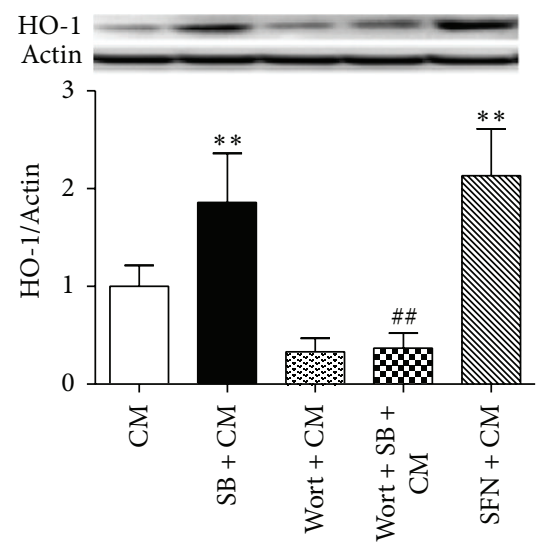

(h)

Figure 3: SB decreased the levels of oxidative stress induced by iohexol through the Akt/GSK-3 $\beta /$ Nrf2 pathway. (a, c) Representative photomicrographs of immunohistochemical staining for the redox product oxidized derivative, 8-OHdG, in renal sections and quantitative analysis of 8-OHdG-positive cells. The 8-OHdG-positive staining was localized in nuclei. (b, e) Representative photomicrographs of immunostaining for Nrf2 in the renal sections and quantitative analysis of the Nrf2-positive cells. The extent of staining for Nrf2 in the nuclear fraction represents their activity. (d) MDA concentrations in the renal tissues. SB resulted in a marked reduction in the number of 8-OHdG-positive cells and the MDA concentrations and a marked increase in the number of Nrf2-positive cells in renal tissues $24 \mathrm{~h}$ after iohexol injection. These effects were inhibited by treatment with wortmannin, and SFN could mimic the effects of SB. (f, g) Representative immunoblots and statistical data of (f) phosphorylated and total Akt (56 KDa), (g) nuclear-Nrf2 (68 KDa), and (h) HO-1 (32K Da) in the renal lysates from rats $3 \mathrm{~h}$ after the injection of iohexol. SB could activate Nrf2/HO-1 by inducing the phosphorylation of Akt, which was inhibited by wortmannin. SFN could activate Nrf2/HO-1. Note that SB protected the kidneys from oxidative stress through the PI3K/Akt/Nrf2 pathway. Original magnification $(\mathrm{a}, \mathrm{b}): \times 200 .{ }^{* *} p<0.01$ versus the $\mathrm{CM}$ group and ${ }^{\# \#} p<0.01$ versus the $\mathrm{SB}+\mathrm{CM}$ group; $n=8$. The values shown are the mean \pm SD. 
addition, a specific inhibitor of PI3K (wortmannin) abolished the antioxidative effects of SB (Figures 3(a), 3(c), and 3(d)).

Only in the nuclear fraction, Nrf2 can exert antioxidative effects. Immunohistochemical staining showed that the numbers of Nrf2-positive cells were more in the $\mathrm{SB}+\mathrm{CM}$ group and SFN + CM group than in the CM group (percentage of Nrf2-positive cells, $28.58 \pm 5.92$ versus $12.93 \pm 4.42, p<0.01$; $26.40 \pm 7.10$ versus $12.93 \pm 4.42, p<0.01$ ) (Figures $3(c)$ and $3(\mathrm{e})$ ). Western blot analysis showed a significant increase in the levels of p-Akt, nuclear-Nrf2, and HO-1 in the SB + CM group compared with the CM group (p-Akt/Akt: $2.08 \pm 0.48$ versus $1.00 \pm 0.25, p<0.01 ; \mathrm{Nrf2}: 2.02 \pm 0.51$ versus $1.00 \pm$ $0.20, p<0.01$; HO-1/Actin: $1.86 \pm 0.50$ versus $1.00 \pm 0.21$, $p<0.01$ ) (Figures $3(\mathrm{f}), 3(\mathrm{~g})$, and $3(\mathrm{~h})$ ). There was a significant increase in the levels of nuclear-Nrf2 and HO-1 in the SFN + CM group compared with the CM group (Nrf2: $2.27 \pm 0.72$ versus $1.00 \pm 0.20, p<0.01 ; \mathrm{HO}-1 /$ Actin: $2.13 \pm 0.48$ versus $1.00 \pm 0.21, p<0.01)$. There was no significant difference in levels of p-Akt between the SFN + CM group and the CM group $(1.07 \pm 0.31$ versus $1.00 \pm 0.25, p>0.05)$ (Figures $3(\mathrm{f})$ and $3(\mathrm{~g})$ ). However, a specific inhibitor of PI3K (wortmannin) decreased the expression of p-Akt, nuclear-Nrf2, and HO-1 (Figures 3(f), 3(g), and 3(h)). The above results showed that $\mathrm{SB}$ exerted antioxidative effects through the PI3K/Akt/Nrf2 pathway.

3.4. Effect of $S B$ on Cellular ROS Levels and Cell Viability Induced by $\mathrm{H}_{2} \mathrm{O}_{2}$ in $\mathrm{HK}-2$ Cells. The effect of SB on cellular ROS levels and the subsequent cell viability induced by $\mathrm{H}_{2} \mathrm{O}_{2}$ were examined using human proximal tubule (HK-2) cells. The cellular ROS production induced by $\mathrm{H}_{2} \mathrm{O}_{2}$ in the $\mathrm{SB}+\mathrm{H}_{2} \mathrm{O}_{2}$ group was significantly lower than that in the $\mathrm{H}_{2} \mathrm{O}_{2}$ group (relative fluorescence units, $114.67 \pm 4.51$ versus $168.00 \pm 17.09, p<0.01$ ) (Figure 4(a)). Furthermore, the subsequent cell viability induced by $\mathrm{H}_{2} \mathrm{O}_{2}$ in the $\mathrm{SB}+\mathrm{H}_{2} \mathrm{O}_{2}$ group was significantly higher than that in the $\mathrm{H}_{2} \mathrm{O}_{2}$ group $(94.33 \pm 4.04$ versus $50.67 \pm 3.06, p<0.01)$ (Figure $4(\mathrm{~b})$ ).

To determine whether the PI3K/Akt/Nrf2 pathway was involved in antioxidative and cell-protective effects of SB, a specific inhibitor of PI3K (wortmannin) was used to abolish the effects of SB. HK-2 cells were transfected with siNrf2 or siCTRL for $6 \mathrm{~h}$ and then treated with $\mathrm{SB}$ and $\mathrm{H}_{2} \mathrm{O}_{2}$. The results showed that the knockdown of Nrf2 partially reversed the inhibitory effects of $\mathrm{SB}$ on the $\mathrm{H}_{2} \mathrm{O}_{2}$-induced ROS production and cellular damage (Figures 4(a) and 4(b)). Western blot analysis showed that SB significantly increased the expression of p-Akt, nuclear-Nrf2 at $24 \mathrm{~h}$ after treatment, which was abolished by wortmannin. siNrf2 significantly reversed SB-induced expression of nuclear-Nrf2 and had no an effect on the p-Akt level (Figures 4(c) and 4(d)). The above results suggested that SB-induced antioxidative and cell-protective activity was mediated via the PI3K/Akt/Nrf2 pathway.

\section{Discussion}

$\mathrm{SB}$, the most abundant and bioactive ingredient in Danshen, is widely applied in the treatment of various cardiovascular diseases [18-20], neural diseases [21, 22], and liver diseases $[23,24]$ and can prevent tubular epithelial-to-mesenchymal transition in the fibrotic kidney induced by $\mathrm{HgCl}_{2}$ as well as HK-2 cells triggered by TGF-betal [25]. However, little is known about its renoprotection against CI-AKI. In the present study, treatment with SB markedly suppressed the deterioration of renal function in a CI-AKI rat model. The experiment revealed that $\mathrm{SB}$ rescued renal tubular injury and prevented apoptosis of renal tubular cells induced by iohexol. The study shows that SB can be effective in preventing kidney damage induced by CM.

Oxidative stress plays a major role in many pathophysiological conditions from a variety of ischaemic/reperfusion or toxic injury [26-30]. Moreover, antioxidants (e.g., $\mathrm{N}$ acetylcysteine [31, 32], statins $[33,34]$, tocopherol $[6,35]$, ascorbic acid [36], Phyllanthus emblica extract [37], and green tea extract [38]) have been successfully used in experimental or clinical trials for renoprotection against CM. Therefore, oxidative stress is involved in the development and progression of CI-AKI. Previous studies with SB have suggested that it possess the organ-protective capabilities by scavenging ROS [39]. In the present study, SB inhibited the development of oxidative stress in kidneys of CI-AKI rats and $\mathrm{H}_{2} \mathrm{O}_{2}$-induced HK-2 cells damage. The above results showed that SB exerted antioxidative effects to protect renal tubular cells against CIAKI.

The CI-AKI model in our study used rats with a form of CKD; this model involves dehydration and a nonpharmacological procedure, which was applied to better mimic the clinical disease [14]. We further explored the underlying mechanisms of SB's renoprotection against CI-AKI. Wang et al. reported that SB pretreatment provided significant protection against arsenic trioxide-induced $\mathrm{H} 9 \mathrm{c} 2$ cardiomyocyte death correlated with the activation of the PI3K/Akt pathway [40]. Previous research has demonstrated that the PI3K/Akt pathway plays a critical role in modulating Nrf2/HO-1 protein expression as an upstream signaling molecule [41]. In this study, we investigated whether the mechanisms of renoprotection conferred by SB involved activation of the $\mathrm{PI} 3 \mathrm{~K} / \mathrm{Akt} / \mathrm{Nrf2}$ pathway. We found that SB induced Akt phosphorylation and activation of Nrf2, decreased the levels of oxidative stress in vivo and in vitro, and attenuated the levels of renal dysfunction, tubular damage, and tubular cell apoptosis. These above effects were abolished by treatment with wortmannin (a specific inhibitor of PI3K). The antioxidant and cell-protective effects of SB were reversed by the knockdown of Nrf2 in vitro. Moreover, an activator of Nrf2, sulforaphane, decreased the levels of oxidative stress as well as attenuated the levels of renal dysfunction, tubular damage, and tubular cell apoptosis in the CI-AKI rat model mimicking the effect of SB. The above results showed that the renoprotection afforded by SB was mediated via the PI3K/Akt/Nrf2 signaling pathway.

Lots of evidence suggests that increased oxidative stress and altered apoptosis are responsible for the pathogenesis of CI-AKI. Oxidative stress in the kidneys is responsible for CI-AKI because it causes significant harmful effects to cellular function, injury to mitochondria, release of apoptosisinducing factors, activation of the caspase cascade, and 


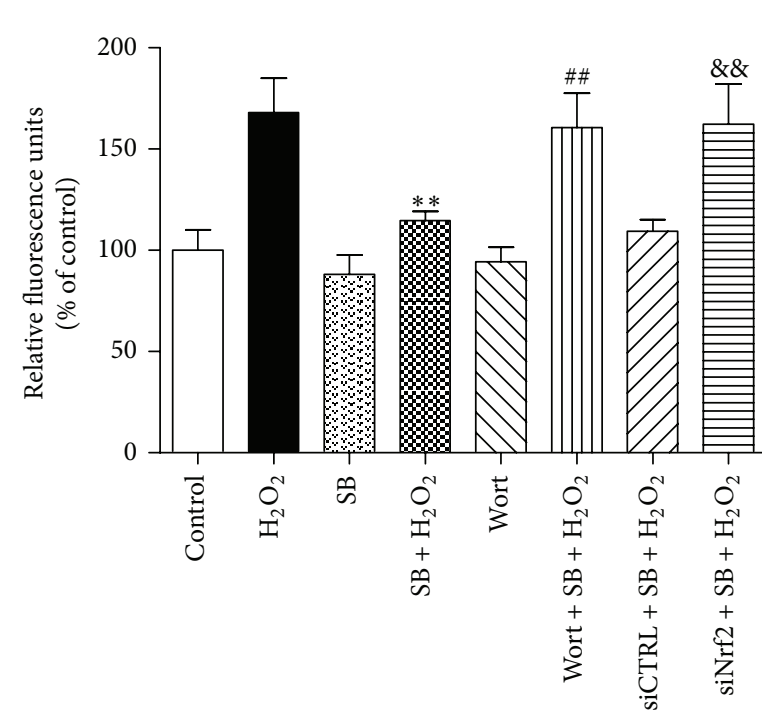

(a)

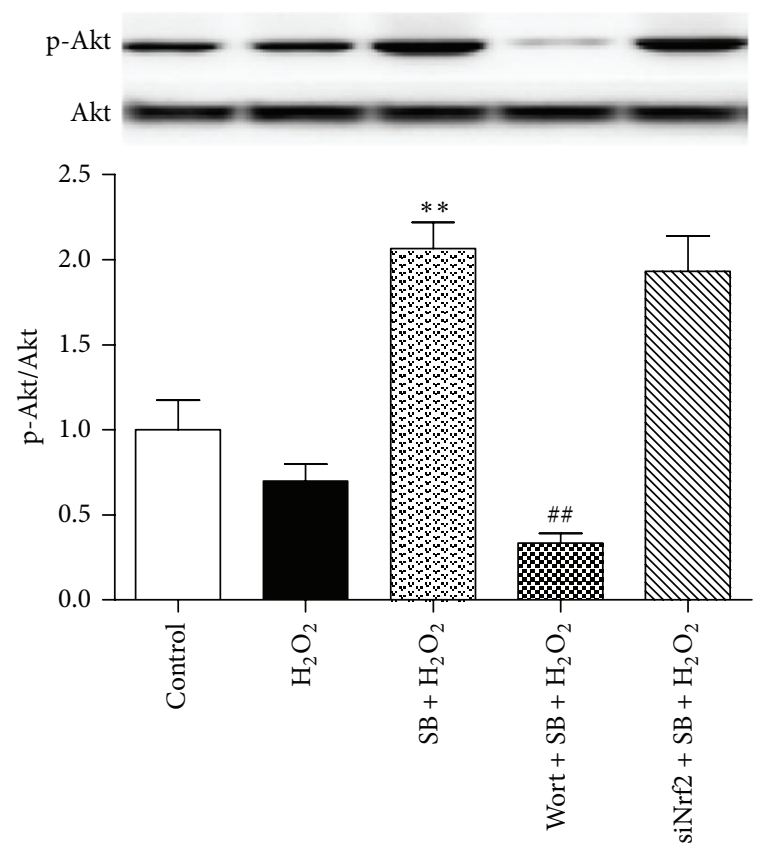

(c)

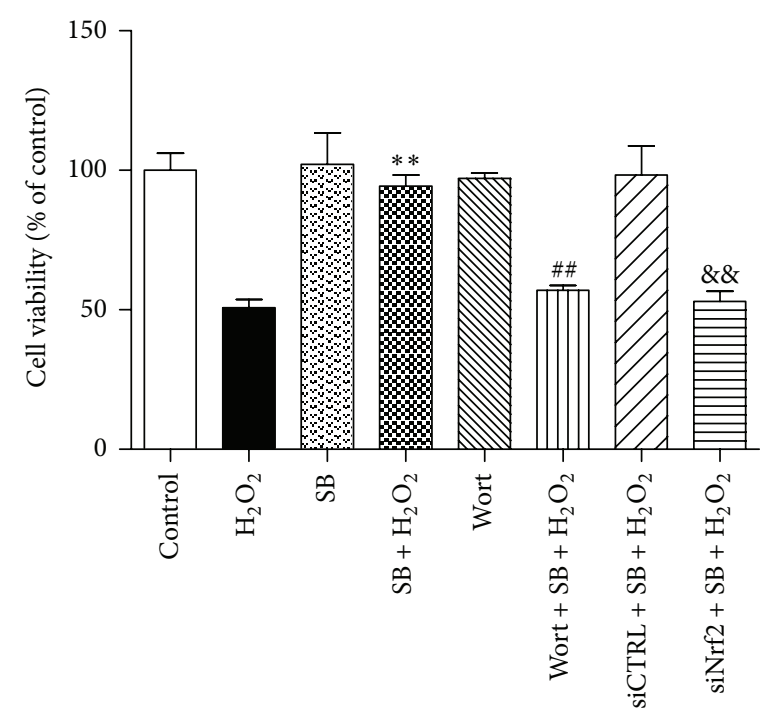

(b)
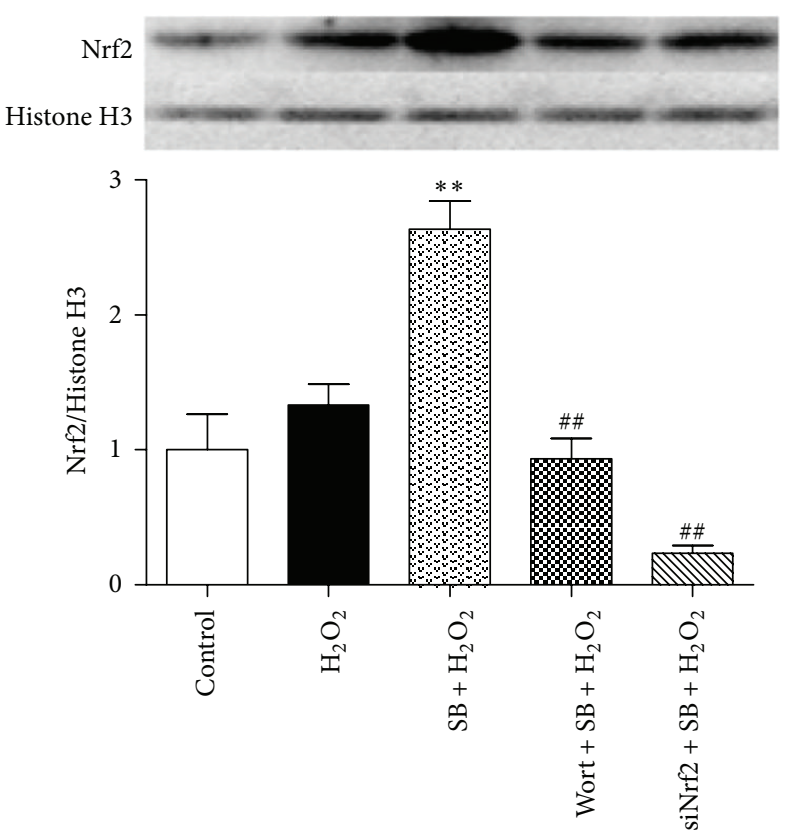

(d)

Figure 4: Effects of SB on ROS levels and the viability of renal tubular epithelial cells injured with $\mathrm{H}_{2} \mathrm{O}_{2}$. (a) HK-2 cells were incubated with $\mathrm{SB}(50 \mu \mathrm{M})$ or vehicle for $1 \mathrm{~h}$ and then incubated with $250 \mathrm{mM} \mathrm{H}_{2} \mathrm{O}_{2}$ or vehicle for $3 \mathrm{~h}$. Fluorescence intensity was measured at an excitation wavelength of $485 \mathrm{~nm}$ and an emission wavelength of $535 \mathrm{~nm}$. (b) HK-2 cells were incubated with SB (50 $\mu \mathrm{M})$ or vehicle for $1 \mathrm{~h}$ and then incubated with $250 \mathrm{mM} \mathrm{H}_{2} \mathrm{O}_{2}$ or vehicle for $24 \mathrm{~h}$ and then incubated with the CCK- 8 solution for $3 \mathrm{~h}$ at $37^{\circ} \mathrm{C}$. The maximum absorption of the strong orange CCK-8 formazan was $450 \mathrm{~nm}$. The viability of HK-2 cells was quantified by optical density (OD) measurements using a spectrophotometer. Treatment with $\mathrm{H}_{2} \mathrm{O}_{2}$ markedly increased cellar ROS levels and decreased cell viability, while treatment with SB decreased cellar ROS levels and improved cell viability. In contrast, the supportive effect of SB was blunted in cells transfected with siNrf2. (c, d) Representative immunoblots and statistical data of (c) phosphorylated and total Akt (56 KDa) and (d) nuclear-Nrf2 (68 KDa) at $24 \mathrm{~h}$ after treatment with $\mathrm{H}_{2} \mathrm{O}_{2}$ or vehicle. SB could activate Nrf2 by inducing the phosphorylation of Akt, which was inhibited by wortmannin. SFN could activate Nrf2. siNrf2 suppressed the expression of nuclear-Nrf2. Note that SB protected the kidneys from oxidative stress through the $\mathrm{PI} 3 \mathrm{~K} / \mathrm{Akt} / \mathrm{Nrf2}$ pathway. ${ }^{* *} p<0.01$ versus the $\mathrm{H}_{2} \mathrm{O}_{2}$ group; ${ }^{\# \#} p<0.01$ versus the $\mathrm{SB}+\mathrm{H}_{2} \mathrm{O}_{2}$ group; and ${ }^{\text {\&\& }} p<0.01$ versus the siCTRL $+\mathrm{SB}$ $+\mathrm{H}_{2} \mathrm{O}_{2}$ group; $n=8$. The values shown are the mean $\pm \mathrm{SD}$. 
damage to nucleic acids, proteins, and membrane lipids [15]. Cytochrome $\mathrm{c}$ in mitochondria released into the cytosol can induce apoptosis by activation of downstream caspases. Mitochondrial DNA is a target for oxidative damage and, when damaged, exacerbates oxidative stress by reducing the production of critical proteins for electron transport. This can result in a vicious circle of ROS production and damage to the kidneys that eventually leads to either renal tubular cells injury or apoptosis [42]. Moreover, ROS generation in medullary tubular is also involved in regulating microcirculation through its effects on nitric oxide levels [43].

This experimental model has revealed that SB is associated with renoprotection, which is an encouraging result with potential clinical applications. Moreover, we found that renoprotection was dependent on activation of Nrf2. Therefore, further studies in this regard will be helpful in exploring this new possible therapeutic agent. We speculate that other Nrf2 activators (e.g., sulforaphane [44]; tBHQ [45]; plumbagin [46]; RS9 [47]; trans-Coniferylaldehyde [48]; and oltipraz [49]) may be promising and effective renoprotective agents due to their antioxidative effects. This study on the $\mathrm{PI} 3 \mathrm{~K} / \mathrm{Akt} / \mathrm{Nrf} 2$ pathway of SB not only uncovered its underlying molecular mechanisms but also opens up a new direction for research for the prevention of CI-AKI by targeting the regulation of Nrf2 activity. Therefore, randomized controlled clinical trials will be necessary to explore the effects of SB or Nrf2 activators on clinical outcomes in patients with renal injury and to demonstrate $\mathrm{SB}$ or Nrf2 activators may be a novel renoprotective strategy.

\section{Conclusion}

$\mathrm{SB}$ can protect against $\mathrm{CI}-\mathrm{AKI}$ in vivo and in vitro. The underlying mechanism by which SB protects against CI-AKI is suppression of oxidative stress through the PI3K/Akt/Nrf2 pathway.

$\begin{array}{ll}\text { Abbreviations } \\ \text { CI-AKI: } & \text { Contrast-induced acute kidney injury } \\ \text { CM: } & \text { Contrast medium } \\ \text { Scr: } & \text { Serum creatinine } \\ \text { ROS: } & \text { Reactive oxygen species } \\ \text { SB: } & \text { Salvianolic acid B } \\ \text { Nrf2: } & \text { Nuclear factor erythroid 2-related factor } 2 \\ \text { HO-1: } & \text { Heme oxygenase 1 } \\ \text { GCLC: } & \text { Glutamate-l-cysteine ligase catalytic subunit } \\ \text { NQO1: } & \text { Quinone oxidoreductase } \\ \text { SFN: } & \text { Sulforaphane } \\ \text { NE: } & \text { Nephrectomy } \\ \text { BUN: } & \text { Blood urea nitrogen } \\ \text { HE: } & \text { Haematoxylin and eosin } \\ \text { TUNEL: } & \text { Terminal deoxynucleotidyl } \\ & \text { transferase-mediated dUTP nick-end labeling } \\ \text { PBS: } & \text { Phosphate-buffered saline } \\ \text { 8-OHdG: } & \text { 8-Hydroxydeoxyguanosine } \\ \text { MDA: } & \text { Malondialdehyde. }\end{array}$

\section{Competing Interests}

The authors declare that there is no conflict of interests regarding the publication of this paper.

\section{Acknowledgments}

This work was supported by Grants 81430015 and 81570600 from the National Natural Science Foundation of China and CJ20159042 from Changzhou Sci \& Tech Program of China.

\section{References}

[1] G. Crimi, S. Leonardi, F. Costa et al., "Incidence, prognostic impact, and optimal definition of contrast-induced acute kidney injury in consecutive patients with stable or unstable coronary artery disease undergoing percutaneous coronary intervention. insights from the all-comer PRODIGY trial," Catheterization and Cardiovascular Interventions, vol. 86, no. 1, pp. E19E27, 2015.

[2] P. Aguiar-Souto, G. Ferrante, F. Del Furia, P. Barlis, R. Khurana, and C. Di Mario, "Frequency and predictors of contrastinduced nephropathy after angioplasty for chronic total occlusions," International Journal of Cardiology, vol. 139, no. 1, pp. 6874, 2010.

[3] M. Abe, T. Morimoto, M. Akao et al., "Relation of contrastinduced nephropathy to long-term mortality after percutaneous coronary intervention," The American Journal of Cardiology, vol. 114, no. 3, pp. 362-368, 2014.

[4] A. L. Jorgensen, "Contrast-induced nephropathy: pathophysiology and preventive strategies," Critical Care Nurse, vol. 33, no. 1, pp. 37-46, 2013.

[5] J. Golshahi, H. Nasri, and M. Gharipour, "Contrast-induced nephropathy; a literature review," Journal of Nephropathology, vol. 3, no. 2, pp. 51-56, 2014.

[6] S. Kongkham, S. Sriwong, and A. Tasanarong, "Protective effect of alpha tocopherol on contrast-induced nephropathy in rats," Nefrologia, vol. 33, no. 1, pp. 116-123, 2013.

[7] T. Kurtoglu, S. Durmaz, C. Akgullu et al., "Ozone preconditioning attenuates contrast-induced nephropathy in rats," Journal of Surgical Research, vol. 195, no. 2, pp. 604-611, 2015.

[8] X.-B. Li, W. Wang, G.-J. Zhou, Y. Li, X.-M. Xie, and T.-S. Zhou, "Production of salvianolic acid B in roots of Salvia miltiorrhiza (Danshen) during the post-harvest drying process," Molecules, vol. 17, no. 3, pp. 2388-2407, 2012.

[9] J. Zhou, X.-D. Qu, Z.-Y. Li et al., "Salvianolic acid B attenuates toxin-induced neuronal damage via Nrf2-dependent glial cellsmediated protective activity in Parkinson's disease models," PLoS ONE, vol. 9, no. 7, Article ID e101668, 11 pages, 2014.

[10] H.-Y. Gao, G.-Y. Li, M.-M. Lou, X.-Y. Li, X.-Y. Wei, and J.-H. Wang, "Hepatoprotective effect of Matrine salvianolic acid bsalt on carbon tetrachloride-induced hepatic fibrosis," Journal of Inflammation, vol. 9, article 16, 2012.

[11] C.-L. Liu, L.-X. Xie, M. Li, S. S. K. Durairajan, S. Goto, and J.-D. Huang, "Salvianolic acid B inhibits hydrogen peroxideinduced endothelial cell apoptosis through regulating PI3K/Akt signaling," PLoS ONE, vol. 2, no. 12, Article ID e1321, 8 pages, 2007.

[12] M. Lin, X. Zhai, G. Wang et al., "Salvianolic acid B protects against acetaminophen hepatotoxicity by inducing Nrf2 and phase II detoxification gene expression via activation of the 
PI3K and PKC signaling pathways," Journal of Pharmacological Sciences, vol. 127, no. 2, pp. 203-210, 2015.

[13] X. Ma, Y.-L. Zhao, Y. Zhu et al., "Paeonia lactiflora Pall. protects against ANIT-induced cholestasis by activating Nrf2 via PI3K/Akt signaling pathway," Drug Design, Development and Therapy, vol. 9, pp. 5061-5074, 2015.

[14] T.-Q. Liu, W.-L. Luo, X. Tan et al., "A novel contrast-induced acute kidney injury model based on the 5/6-nephrectomy rat and nephrotoxicological evaluation of iohexol and iodixanol in vivo," Oxidative Medicine and Cellular Longevity, vol. 2014, Article ID 427560, 14 pages, 2014.

[15] T. Liu, Y. Fang, S. Liu et al., "Limb ischemic preconditioning protects against contrast-induced acute kidney injury in rats via phosphorylation of GSK-3 $\beta$," Free Radical Biology and Medicine, vol. 81, pp. 170-182, 2015.

[16] S. Dwivedi, N. Rajasekar, K. Hanif, C. Nath, and R. Shukla, "Sulforaphane ameliorates okadaic acid-induced memory impairment in rats by activating the $\mathrm{Nrf} 2 / \mathrm{HO}-1$ antioxidant pathway," Molecular Neurobiology, pp. 1-14, 2015.

[17] X. Chen, J. Liu, and S.-Y. Chen, "Sulforaphane protects against ethanol-induced oxidative stress and apoptosis in neural crest cells by the induction of Nrf2-mediated antioxidant response," British Journal of Pharmacology, vol. 169, no. 2, pp. 437-448, 2013.

[18] S. Xu, A. Zhong, X. Bu et al., "Salvianolic acid B inhibits platelets-mediated inflammatory response in vascular endothelial cells," Thrombosis Research, vol. 135, no. 1, pp. 137-145, 2015.

[19] J. Wang, X. J. Xiong, and B. Feng, "Cardiovascular effects of salvianolic acid B," Evidence-Based Complementary and Alternative Medicine, vol. 2013, Article ID 247948, 16 pages, 2013.

[20] Y. Tang, A. Jacobi, C. Vater, X. Zou, and M. Stiehler, "Salvianolic acid B protects human endothelial progenitor cells against oxidative stress-mediated dysfunction by modulating Akt/ mTOR/4EBP1, p38 MAPK/ATF2, and ERK1/2 signaling pathways," Biochemical Pharmacology, vol. 90, no. 1, pp. 34-49, 2014.

[21] N. Zhang, T. Kang, Y. Xia et al., "Effects of salvianolic acid B on survival, self-renewal and neuronal differentiation of bone marrow derived neural stem cells," European Journal of Pharmacology, vol. 697, no. 1-3, pp. 32-39, 2012.

[22] P. Zhuang, Y. Zhang, G. Cui et al., "Direct stimulation of adult neural stem/progenitor cells in vitro and neurogenesis in vivo by salvianolic acid B," PLoS ONE, vol. 7, no. 4, Article ID e35636, 9 pages, 2012.

[23] Y.-Y. Tao, Q.-L. Wang, L. Shen, W.-W. Fu, and C.-H. Liu, "Salvianolic acid B inhibits hepatic stellate cell activation through transforming growth factor beta-1 signal transduction pathway in vivo and in vitro," Experimental Biology and Medicine, vol. 238, no. 11, pp. 1284-1296, 2013.

[24] R. Wang, X.-Y. Yu, Z.-Y. Guo, Y.-J. Wang, Y. Wu, and Y.-F. Yuan, "Inhibitory effects of salvianolic acid B on CCl4-induced hepatic fibrosis through regulating NF- $\kappa \mathrm{B} / \mathrm{I} \kappa \mathrm{B} \alpha$ signaling," Journal of Ethnopharmacology, vol. 144, no. 3, pp. 592-598, 2012.

[25] Q.-L. Wang, Y.-Y. Tao, J.-L. Yuan, L. Shen, and C.-H. Liu, "Salvianolic acid B prevents epithelial-to-mesenchymal transition through the TGF- $\beta 1$ signal transduction pathway in vivo and in vitro," BMC Cell Biology, vol. 11, article 31, 16 pages, 2010.

[26] R. S. Ferrari and C. F. Andrade, "Oxidative stress and lung ischemia-reperfusion injury," Oxidative Medicine and Cellular Longevity, vol. 2015, Article ID 590987, 14 pages, 2015.

[27] M. Hadadha, A. Vakili, and A. R. Bandegi, "Effect of the inhibition of hydrogen sulfide synthesis on ischemic injury and oxidative stress biomarkers in a transient model of focal cerebral ischemia in rats," Journal of Stroke and Cerebrovascular Diseases, vol. 24, no. 12, pp. 2676-2684, 2015.

[28] A. Rashikh, K. K. Pillai, S. J. Ahmad, M. Akhtar, and A. K. Najmi, "Aliskiren alleviates doxorubicin-induced nephrotoxicity by inhibiting oxidative stress and podocyte injury," Journal of the Renin-Angiotensin-Aldosterone System, vol. 14, no. 1, pp. 1422, 2013.

[29] N. H. Urrunaga, R. N. Jadeja, V. Rachakonda et al., "M1 muscarinic receptors modify oxidative stress response to acetaminophen-induced acute liver injury," Free Radical Biology \& Medicine, vol. 78, pp. 66-81, 2016.

[30] E. Tahmasbpour, S. Reza Emami, M. Ghanei, and Y. Panahi, "Role of oxidative stress in sulfur mustard-induced pulmonary injury and antioxidant protection," Inhalation Toxicology, vol. 27, no. 13, pp. 659-672, 2015.

[31] J. Šochman, J. H. Peregrin, M. Bürgelová, L. Kopkan, H. J. Kramer, and L. Červenka, "N-acetylcysteine attenuates iodine contrast agent-induced nephropathy in 5/6-nephrectomized rats," Kidney and Blood Pressure Research, vol. 33, no. 2, pp. 149156, 2010.

[32] F. Koc, K. Ozdemir, M. G. Kaya et al., "Intravenous Nacetylcysteine plus high-dose hydration versus high-dose hydration and standard hydration for the prevention of contrast-induced nephropathy: CASIS—a multicenter prospective controlled trial," International Journal of Cardiology, vol. 155, no. 3, pp. 418-423, 2012.

[33] F. Tropeano, M. Leoncini, A. Toso et al., "Impact of rosuvastatin in contrast-induced acute kidney injury in the elderly: post Hoc analysis of the PRATO-ACS trial," Journal of Cardiovascular Pharmacology and Therapeutics, vol. 21, no. 2, pp. 159-166, 2016.

[34] B. Qiao, J. Deng, Y. Li, X. Wang, and Y. Han, "Rosuvastatin attenuated contrast-induced nephropathy in diabetes patients with renal dysfunction," International Journal of Clinical and Experimental Medicine, vol. 8, no. 2, pp. 2342-2349, 2015.

[35] A. Tasanarong, A. Vohakiat, P. Hutayanon, and D. Piyayotai, "New strategy of $\alpha$ - and $\gamma$-tocopherol to prevent contrastinduced acute kidney injury in chronic kidney disease patients undergoing elective coronary procedures," Nephrology Dialysis Transplantation, vol. 28, no. 2, pp. 337-344, 2013.

[36] U. Sadat, A. Usman, J. H. Gillard, and J. R. Boyle, “Does ascorbic acid protect against contrast-induced acute kidney injury in patients undergoing coronary angiography: a systematic review with meta-analysis of randomized, controlled trials," Journal of the American College of Cardiology, vol. 62, no. 23, pp. 2167-2175, 2013.

[37] A. Tasanarong, S. Kongkham, and A. Itharat, "Antioxidant effect of Phyllanthus emblica extract prevents contrast-induced acute kidney injury," BMC Complementary and Alternative Medicine, vol. 14, article 138, 11 pages, 2014.

[38] H. Nasri, A. Ahmadi, A. Baradaran et al., "A biochemical study on ameliorative effect of green tea (Camellia sinensis) extract against contrast media induced acute kidney injury.," Journal of Renal Injury Prevention, vol. 3, no. 2, pp. 47-49, 2014.

[39] W. Cao, X.-W. Guo, H.-Z. Zheng, D.-P. Li, G.-B. Jia, and J. Wang, "Current progress of research on pharmacologic actions of salvianolic acid B," Chinese Journal of Integrative Medicine, vol. 18, no. 4, pp. 316-320, 2012.

[40] M. Wang, G.-B. Sun, X. Sun et al., "Cardioprotective effect of salvianolic acid B against arsenic trioxide-induced injury in cardiac $\mathrm{H} 9 \mathrm{c} 2$ cells via the PI3K/Akt signal pathway," Toxicology Letters, vol. 216, no. 2-3, pp. 100-107, 2013. 
[41] X. Xu, H. Li, X. Hou et al., "Punicalagin induces Nrf2/HO-1 expression via upregulation of PI3K/AKT pathway and inhibits LPS-induced oxidative stress in RAW264.7 macrophages," Mediators of Inflammation, vol. 2015, Article ID 380218, 11 pages, 2015.

[42] M. Naziroglu, N. Yoldaş, E. N. Uzgur, and M. Kayan, "Role of contrast media on oxidative stress, $\mathrm{Ca}^{2+}$ signaling and apoptosis in kidney," The Journal of Membrane Biology, vol. 246, no. 2, pp. 91-100, 2013.

[43] A. Pisani, E. Riccio, M. Andreucci et al., "Role of reactive oxygen species in pathogenesis of radiocontrast-induced nephropathy," BioMed Research International, vol. 2013, Article ID 868321, 6 pages, 2013.

[44] Y. Shinkai, D. Sumi, I. Fukami, T. Ishii, and Y. Kumagai, "Sulforaphane, an activator of Nrf2, suppresses cellular accumulation of arsenic and its cytotoxicity in primary mouse hepatocytes," FEBS Letters, vol. 580, no. 7, pp. 1771-1774, 2006.

[45] J. W. Zagorski, A. E. Turley, H. E. Dover, K. R. VanDenBerg, J. R. Compton, and C. E. Rockwell, "The Nrf2 activator, tBHQ, differentially affects early events following stimulation of Jurkat cells," Toxicological Sciences, vol. 136, no. 1, pp. 63-71, 2013.

[46] T. G. Son, S. Camandola, T. V. Arumugam et al., "Plumbagin, a novel Nrf2/ARE activator, protects against cerebral ischemia," Journal of Neurochemistry, vol. 112, no. 5, pp. 1316-1326, 2010.

[47] Y. Nakagami, E. Hatano, T. Inoue, K. Yoshida, M. Kondo, and H. Terasaki, "Cytoprotective effects of a novel Nrf2 activator, RS9, in rhodopsin Pro347leu rabbits," Current Eye Research, 2015.

[48] H.-H. Chen, T.-C. Wang, Y.-C. Lee et al., "Novel Nrf2/ARE activator, trans-coniferylaldehyde, induces a HO-1-mediated defense mechanism through a dual p38 $\alpha$ /MAPKAPK-2 and PK-N3 signaling pathway," Chemical Research in Toxicology, vol. 28, no. 9, pp. 1681-1692, 2015.

[49] M. D. Merrell, J. P. Jackson, L. M. Augustine et al., "The Nrf2 activator oltipraz also activates the constitutive androstane receptor," Drug Metabolism and Disposition, vol. 36, no. 8, pp. 1716-1721, 2008. 


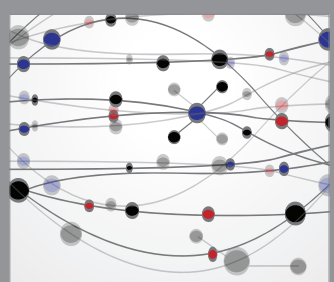

The Scientific World Journal
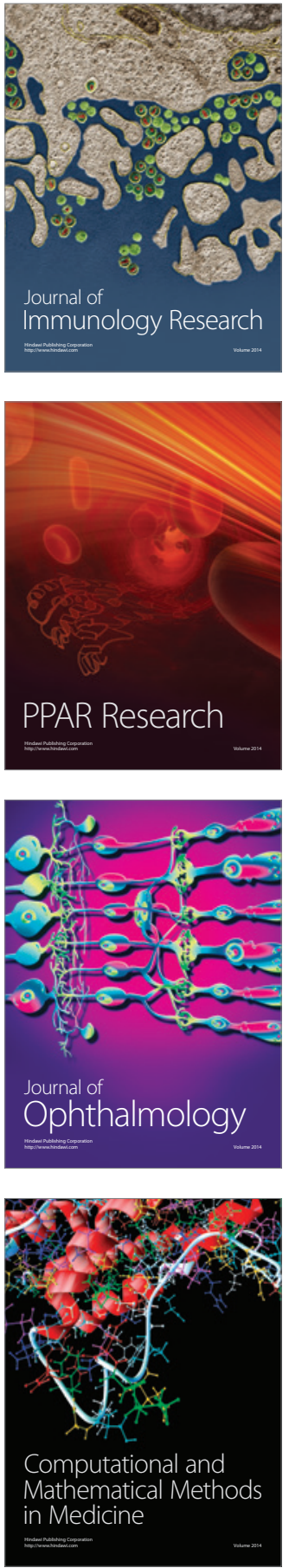

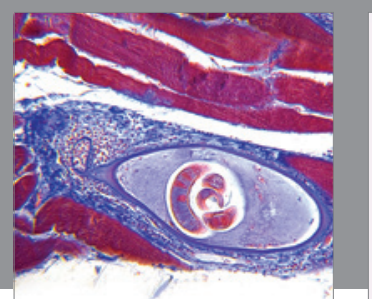

Gastroenterology Research and Practice

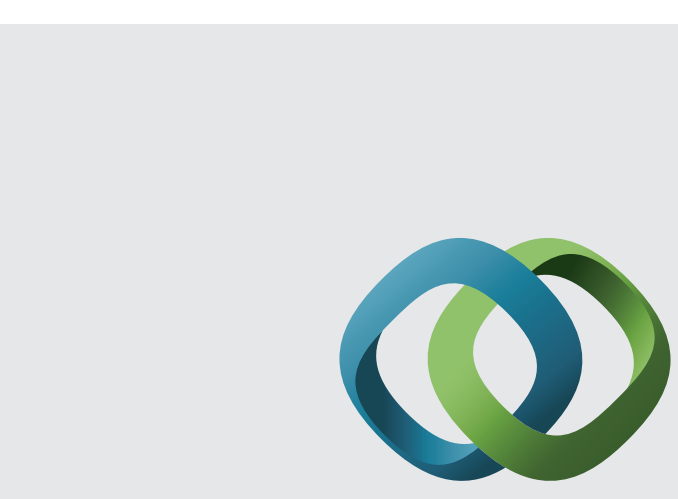

\section{Hindawi}

Submit your manuscripts at

http://www.hindawi.com
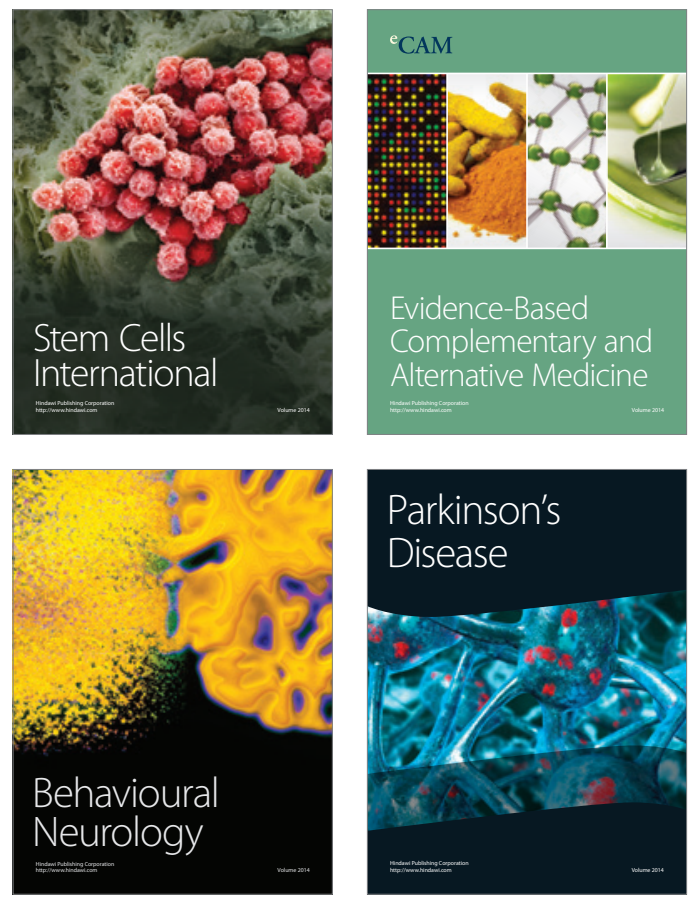
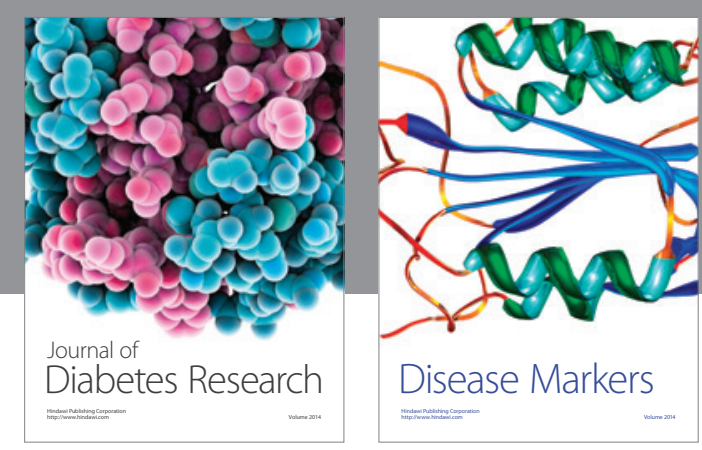

Disease Markers
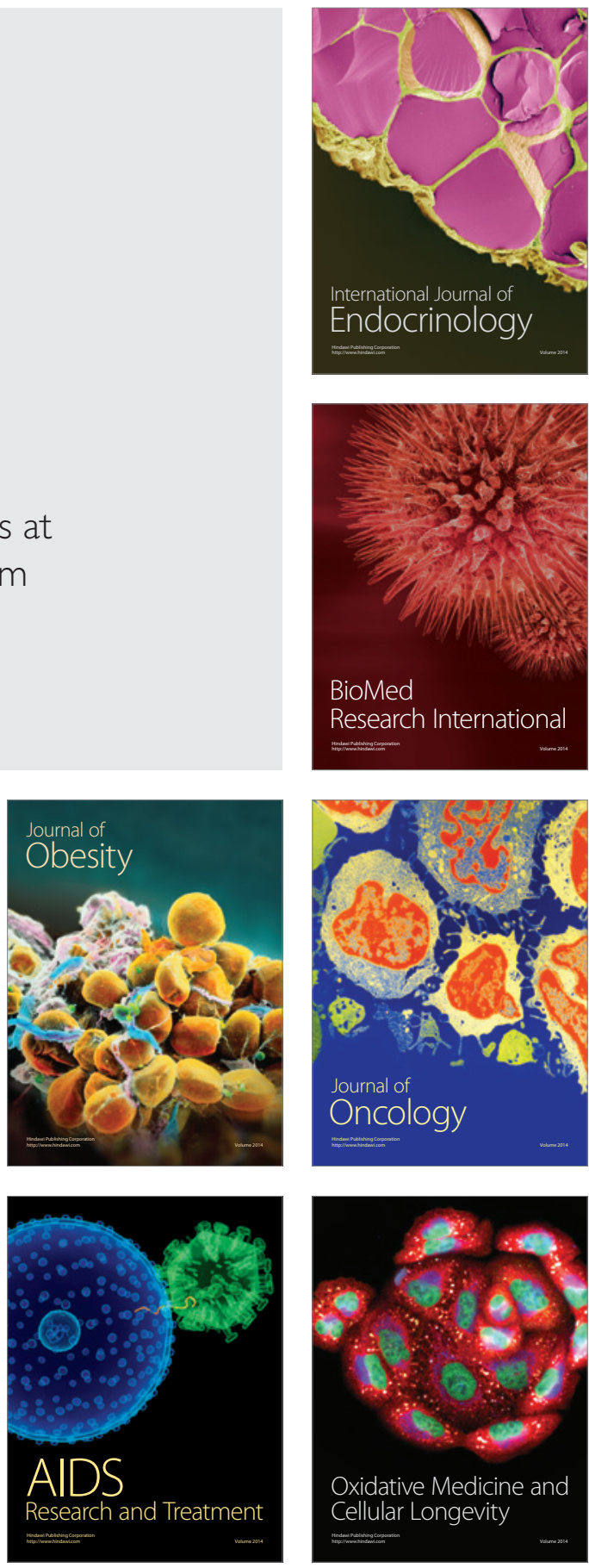